\title{
Tiotropium discontinuation in patients with early-stage COPD: a prospective observational cohort study
}

\author{
Chenglong $\mathrm{Li}^{1,4}$, Yumin Zhou ${ }^{1,4}$, Sha Liu ${ }^{1,2}$, Mengning Zheng ${ }^{1,3}$, Jinzhen Zheng ${ }^{1}$, \\ Huanhuan Peng ${ }^{1}$, Zhishan Deng ${ }^{1}$, Nanshan Zhong ${ }^{1}$ and Pixin Ran (i] ${ }^{1}$
}

Affiliations: ${ }^{1}$ The State Key Laboratory of Respiratory Disease, National Clinical Researcher Center for Respiratory Diseases, Guangzhou Institute of Respiratory Health, The First Affiliated Hospital, Guangzhou Medical University, Guangzhou, China. ${ }^{2}$ Department of Respiratory and Critical Care Medicine, the Second Affiliated Hospital of the University of South China, Hunan, China. ${ }^{3}$ Department of Respiratory and Critical Care Medicine, Guizhou Provincial People's Hospital, Guiyang, China. ${ }^{4}$ These authors contributed equally to this study.

Correspondence: Pixin Ran, The State Key Laboratory of Respiratory Disease, National Clinical Researcher Center for Respiratory Diseases, Guangzhou Institute of Respiratory Health, The First Affiliated Hospital, Guangzhou Medical University, Yanjiang Rd 195, Guangzhou, Guangdong 510182, China.

E-mail: pxrandgzhmu.edu.cn

\section{ABSTRACT}

Background: Tiotropium improves lung function and ameliorates the annual decline in forced expiratory volume in $1 \mathrm{~s}(\mathrm{FEV} 1)$ after bronchodilator use in patients with mild to moderate chronic obstructive pulmonary disease (COPD). However, whether these benefits persist in patients with early-stage COPD after tiotropium discontinuation is unknown.

Methods: In this prospective cohort observational follow-up study, patients who had completed the Tiotropium in Early-Stage COPD (Tie-COPD) trial were followed for a maximum of 3 years, continuing or discontinuing treatment according to their willingness. The outcomes measured were spirometry parameters, COPD exacerbations, COPD Assessment Test (CAT) scores, Clinical COPD Questionnaire (CCQ) scores, modified Medical Research Council (mMRC) scores and the use of respiratory medications. Results: Out of 376 patients, 262 (126 in the post-placebo group and 136 in the post-tiotropium group) completed the maximum 3-year follow-up after the study medication was withdrawn. After discontinuation, the decrease in FEV1 and forced vital capacity (FVC) did not differ significantly between the two groups, and neither did their annual decline. In addition, the frequency of acute COPD exacerbations and the MMRC scores were similar between the two groups after medication withdrawal. Both the mean CAT and CCQ scores were significantly lower in the post-tiotropium group than in the post-placebo group ( $\mathrm{p}<0.05$ for all comparisons) at the 1-year follow-up after withdrawal, but they were not different at the next follow-up.

Conclusion: Withdrawal of tiotropium treatment in early-stage COPD resulted in difference reduction of both FEV1 and FVC, indicating that treatment should be continued.

@ERSpublications

Tiotropium improves lung function and ameliorates the annual decline in early-stage COPD patients. In order to maintain continuous improvement of the pulmonary function, continuous drug intervention is needed. http://ow.ly/ASNx30n4Kdo

Cite this article as: Li C, Zhou Y, Liu S, et al. Tiotropium discontinuation in patients with earlystage COPD: a prospective observational cohort study. ERJ Open Res 2019; 5: 00175-2018 [https:// doi.org/10.1183/23120541.00175-2018].

This article has supplementary material available from openres.ersjournals.com

Received: Oct 022018 | Accepted after revision: Dec 082018

This study is registered at www.ClinicalTrials.gov with identifier number NCT01455129 for Tie-COPD and at www.chictr.org.cn with identifier number ChiCTR1800017497 for post-Tie-COPD.

Copyright $\odot$ ERS 2019. This article is open access and distributed under the terms of the Creative Commons Attribution Non-Commercial Licence 4.0. 


\section{Introduction}

Chronic obstructive pulmonary disease (COPD), a preventable and treatable disease with a high prevalence $[1,2]$, accounted for $6 \%$ of all deaths globally in 2012 and is projected to be the third leading cause of death worldwide by $2020[3,4]$. Epidemiological studies have shown that $>70 \%$ of patients with COPD are in the early stage of the disease (Global Initiative for Chronic Obstructive Lung Disease (GOLD) stage I-II) [4, 5], with limited respiratory symptoms, but a progressive decline in pulmonary function [6-9]. According to the most recent epidemiological data in China, up to $92.7 \%$ of patients with COPD are in the early stages of the disease [10].

Bronchodilator medications are central to the management of airway obstruction. In a previous study (Tiotropium in Early-Stage COPD (Tie-COPD)), we confirmed the efficacy of tiotropium in improving lung function as shown by amelioration of the annual decline in the forced expiratory volume in $1 \mathrm{~s}$ (FEV1) after bronchodilator use in patients with COPD GOLD stage I or II [11]. However, due to the long-term nature of COPD, whether periodic long-term treatment impacts the course of COPD remains unknown, and no clinical trials to date have conducted follow-up studies addressing this problem [12-16].

Tiotropium is an inhaled anticholinergic bronchodilator with a sustained bronchodilation effect due to the prolonged dissociation from the muscarinic $\mathrm{M}_{3}$ receptor (half-life $\sim 35 \mathrm{~h}$ ) [17]. The most recent clinical trial and post hoc evidence showed that early intervention using tiotropium seems to be effective in preventing this progressive disease course $[8,11]$. Post hoc evidence showed that the withdrawal of tiotropium after 1-year maintenance treatment resulted in worsening of COPD over a 3-week interval, as indicated by worsening of the transition dyspnoea index and decreases in peak expiratory flow rate and health status [18]. However, this study did not refer to spirometry data. Whether a rebound effect exists in response to tiotropium withdrawal is unknown, especially in terms of a long-term decline in lung function.

In our previous study, patients with COPD GOLD stage I or II experienced amelioration in FEV1 and an annual decline in the $\mathrm{FEV}_{1}$ after bronchodilator use following 2-year maintenance treatment with tiotropium [11]. We conducted a 3-year follow-up study to assess whether periodic long-term treatment with tiotropium impacts the lung function decline in patients with early-stage COPD.

\section{Materials and methods}

\section{Design and study patients}

This was a maximum 3-year observational follow-up study after the 2-year Tie-COPD trial in three centres in Guangdong, China. Prior to this study, the patients had completed the 2-year Tie-COPD trial between October 2011 and September 2015, receiving maintenance treatment with tiotropium or matching placebo in early-stage COPD [19]. Those patients who had completed the Tie-COPD trial were then included in a maximum 3-year observational follow-up, according to their willingness to participate. Medication was not restricted and all concomitant use of medications was recorded during the 3-year follow-up period. However, those patients who were using anticholinergics regularly were excluded from the analysis, because this study was performed mainly to observe the dynamic changes in the observation indexes after withdrawal of the study medication from the Tie-COPD trial. All follow-up work was performed independently by our research group from the State Key Laboratory of Respiratory Disease in the First Affiliated Hospital of Guangzhou Medical University (Guangzhou, China). The remaining centres provided site support only.

\section{Procedures}

During this observational follow-up period, clinical visits were scheduled at the first month following withdrawal and every 24 months thereafter. The data that were collected at each visit included symptom scores, medications, COPD exacerbation, smoking status, adverse events and spirometry parameters.

Spirometry tests were performed every 24 months at approximately the same time of day at each visit by well-trained technicians according to international standards [20]. Short-acting bronchodilators were withdrawn for $\geqslant 6 \mathrm{~h}$ before spirometry was performed. Airway reversibility was assessed via bronchodilation, with inhalation of $400 \mu \mathrm{g}$ of salbutamol $20 \mathrm{~min}$ after baseline spirometry.

Acute exacerbation of COPD was defined as previously described and was recorded at every visit [11]. Assessments using the modified Medical Research Council (mMRC) dyspnoea scale and quality-of-life assessments using the COPD Assessment Test (CAT) and Clinical COPD Questionnaire (CCQ) were also performed at each visit [21, 22]. In addition, self-reported smoking status, medications administered and adverse events were recorded at each visit. All criteria of the observation indicators complied with the standards of the previous Tie-COPD study [19]. 
Trial oversight

The trial protocol was approved by the local institutional review board or independent ethics committee at each site according to the requirement of the Chinese guidelines for good clinical practice. All participants provided written informed consent before enrolment. Statistical analyses were performed by employees of Rundo International Pharmaceutical Research \& Development (Shanghai, China). The funding sources had no role in the design, data analysis or interpretation of the results of this trial. Albuterol was purchased at full cost. The first and last authors vouch for the accuracy and completeness of the data and analyses reported and for the fidelity of the trial to the protocol. All authors approved the submission of the manuscript for publication.

\section{Statistical analysis}

Multiple linear regression was used to compare the between-group difference and the annual declines in FEV1 and forced vital capacity (FVC) before and after bronchodilator use, as well as the CAT and CCQ scores at each visit. For each follow-up visit, the measured value was the dependent variable, and covariates included the individual baseline value, baseline smoking status, treatment allocation and participating centre. For 36-60 months, the p-value was computed using the individual baseline value, smoking status across the whole follow-up, use of bronchiectasis medication, treatment allocation and participating centre as covariates. The frequency of acute exacerbation of COPD was compared with the Poisson regression model with correction for exposure of treatment doses and overdispersion. A transfer table was used to compare the changes in the mMRC scores. p-values were derived from the Cochran-Mantel-Haenszel test. All analyses were performed using SAS software for Windows (v. 9.2.2; SAS Institute, Cary, NC, USA). A p-value of $<0.05$ was considered statistically significant.

\section{Results}

\section{Baseline characteristics}

Out of 376 patients with GOLD stage I or II COPD who underwent randomisation in the Tie-COPD study in Guangdong, 262 patients (126 patients in the post-placebo group and 136 in the post-treatment group) completed a maximum 3-year follow-up after study medication withdrawal (figure 1). All

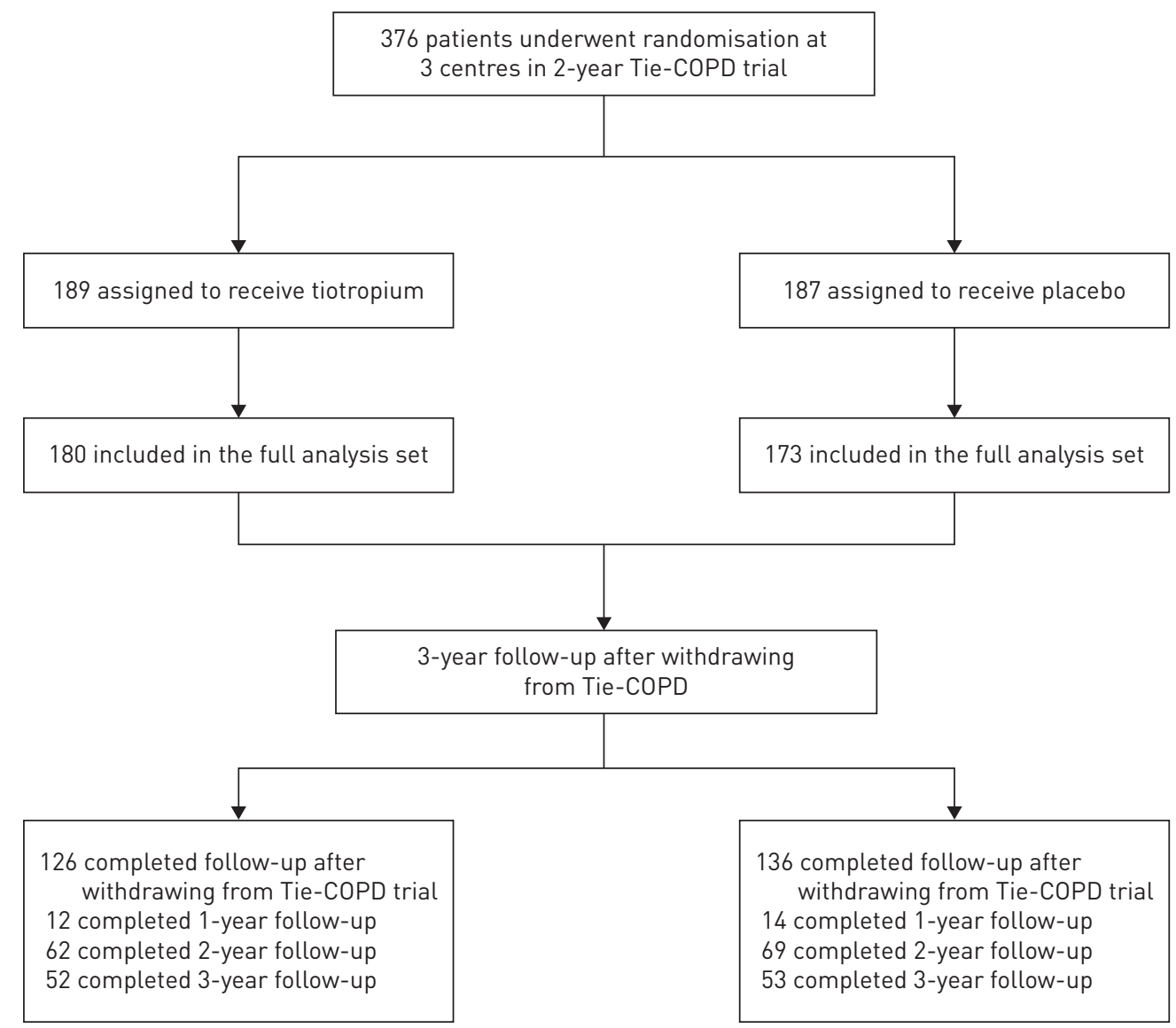

FIGURE 1 Study flow chart. Tie-COPD: Tiotropium in Early-Stage COPD (chronic obstructive pulmonary disease). 
demographic data and clinical characteristics of these patients were comparable at the baseline of the Tie-COPD study and there was no difference in the number of patients using respiratory medications or in the smoking status during and after the Tie-COPD study (table 1).

\section{Lung function}

Although tiotropium resulted in a higher FEV1 and FVC than placebo at each visit in the Tie-COPD trial, both FEV 1 and FVC decreased after discontinuation of tiotropium (figure 2 and supplementary table S1). At the first month after tiotropium withdrawal, $\mathrm{FEV}_{1}$ in the post-tiotropium and post-placebo groups was as follows: before bronchodilator use $1.89 \pm 0.02$ versus $1.79 \pm 0.02 \mathrm{~L}$ with a difference of 0.10 (95\% CI 0.04-0.16) L, $\mathrm{p}=0.0018$ ); after bronchodilator use $1.99 \pm 0.02$ versus $1.92 \pm 0.02 \mathrm{~L}$ with a difference of 0.07 (95\% CI 0.01-0.13) L, p=0.0145). 1 year after tiotropium withdrawal, there was no significant difference in FEV1 either before or after bronchodilator use between the two groups. In the first year of withdrawal, FEV 1 in the treatment and placebo groups was as follows: before bronchodilator use $1.78 \pm 0.04$ versus $1.71 \pm 0.04 \mathrm{~L}(\mathrm{p}=0.12)$; after bronchodilator use $1.85 \pm 0.04$ versus $1.81 \pm 0.04 \mathrm{~L}(\mathrm{p}=0.31)$. In the second year of tiotropium withdrawal, $\mathrm{FEV} 1$ in the treatment and placebo groups was as follows: before bronchodilator use $1.74 \pm 0.03$ versus $1.70 \pm 0.03 \mathrm{~L}$ ( $\mathrm{p}=0.23$ ); after bronchodilator use $1.85 \pm 0.03$ versus $1.84 \pm 0.03 \mathrm{~L}(\mathrm{p}=0.79$ ). In the third year of tiotropium withdrawal, FEV 1 in the treatment and placebo groups was as follows: before bronchodilator use $1.77 \pm 0.03$ versus $1.69 \pm 0.03 \mathrm{~L}$ ( $\mathrm{p}=0.18$ ); after bronchodilator use $1.84 \pm 0.03$ versus $1.80 \pm 0.03 \mathrm{~L}(\mathrm{p}=0.36)$ (figure 2 and table 2 ).

Similar changes in FVC are shown in figure 2 and table 2. At the first month after tiotropium withdrawal, FVC in the treatment and placebo groups was as follows: before bronchodilator use $3.10 \pm 0.03$ versus $3.02 \pm 0.03 \mathrm{~L}$ with a difference of $0.08(95 \% \mathrm{CI}-0.01-0.18) \mathrm{L}(\mathrm{p}=0.09)$; after bronchodilator use $3.17 \pm 0.03$ versus $3.13 \pm 0.03 \mathrm{~L}(\mathrm{p}=0.36)$. 1 year after tiotropium withdrawal, there was no significant difference in FVC either before or after bronchodilator use between the two groups. In the first year of tiotropium withdrawal, FVC in the treatment and placebo groups was as follows: before bronchodilator use $2.99 \pm 0.06$ versus $2.93 \pm 0.06 \mathrm{~L}$ ( $\mathrm{p}=0.41$ ); after bronchodilator use $3.06 \pm 0.05$ versus $3.03 \pm 0.05 \mathrm{~L}$ ( $\mathrm{p}=0.66)$. In the second year of tiotropium withdrawal, FVC in the treatment and placebo groups was as follows: before bronchodilator use $2.93 \pm 0.05$ versus $2.91 \pm 0.05 \mathrm{~L}$ ( $\mathrm{p}=0.67$ ); after bronchodilator use $3.07 \pm 0.05$ versus $3.10 \pm 0.05 \mathrm{~L}(\mathrm{p}=0.67)$. In the third year of tiotropium withdrawal, FVC in the treatment and placebo groups was as follows: before bronchodilator use $3.01 \pm 0.07$ versus $2.89 \pm 0.07 \mathrm{~L} \quad(\mathrm{p}=0.21)$; after bronchodilator use $3.10 \pm 0.06$ versus $3.00 \pm 0.06 \mathrm{~L}$ ( $\mathrm{p}=0.23$ ) (figure 1 and table 2 ).

There was no significant difference in the annual decline of FEV1 and FVC between the two groups at the Tie-COPD trial (supplementary table S2). After tiotropium withdrawal, the tiotropium treatment group showed no difference in the annual decline of FEV1 before and after bronchodilator use compared with the placebo group (before bronchodilator use $21 \pm 20$ versus $31 \pm 21 \mathrm{~mL} \cdot \mathrm{year}^{-1}$ with a difference of $10 \mathrm{~mL} \cdot \mathrm{year}^{-1}, 95 \%$ CI $-47-67 \mathrm{~mL} \cdot \mathrm{year}^{-1}$; $\mathrm{p}=0.73$; after bronchodilator use $48 \pm 15$ versus $68 \pm 16 \mathrm{~mL} \cdot \mathrm{year}^{-1}$ with a difference of $20 \mathrm{~mL} \cdot \mathrm{year}^{-1}, 95 \% \mathrm{CI}-24-64 \mathrm{~mL} \cdot \mathrm{year}^{-1} ; \mathrm{p}=0.37$ ) (table 3). After tiotropium withdrawal, the tiotropium treatment group showed no difference in the annual decline of FVC before and after bronchodilator use compared with the placebo group (before bronchodilator use $26 \pm 33$ versus $40 \pm 35 \mathrm{~mL} \cdot$ year $^{-1}$ with a difference of $14 \mathrm{~mL} \cdot \mathrm{year}^{-1}$, 95\% CI $-80-107 \mathrm{~mL} \cdot \mathrm{year}^{-1}$; $\mathrm{p}=0.77$; after bronchodilator use $23 \pm 29$ versus $59 \pm 31 \mathrm{~mL} \cdot \mathrm{year}^{-1}$ with a difference of $36 \mathrm{~mL} \cdot \mathrm{year}^{-1}$, $95 \%$ CI $-46-118 \mathrm{~mL} \cdot$ year $^{-1} ; \mathrm{p}=0.39$ ) (table 3).

\section{Acute exacerbations of COPD}

In the Tie-COPD trial, tiotropium resulted in a lower frequency of acute exacerbations of COPD than placebo (supplementary table S3). After tiotropium withdrawal, the post-tiotropium treatment group showed no difference in the frequency of acute exacerbations of COPD compared with the post-placebo group (table 4).

\section{Quality-of-life assessment}

In the Tie-COPD trial, tiotropium was more effective than placebo with regard to CAT at months 21 and 24; CCQ at months 9, 18, 21 and 24; and mMRC dyspnoea scale at months 6 and 15 (supplementary tables S4-S6).

At 1 year after tiotropium withdrawal, the mean CAT and CCQ scores were significantly lower in the tiotropium group than placebo group (mean CAT scores $7.8 \pm 0.8$ versus $10.1 \pm 0.8, \mathrm{p}=0.0166$; mean CCQ scores $9.6 \pm 0.9$ versus $11.7 \pm 0.8, \mathrm{p}=0.0342$ ), but no difference was observed in the mean CAT or CCQ scores between the two groups at the second or third year after tiotropium withdrawal (supplementary tables S4 and S5). No difference was observed in the mMRC scores between the two groups during the whole withdrawal period (supplementary table S6). 


\begin{tabular}{|c|c|c|c|}
\hline & Placebo & Tiotropium & p-value \\
\hline Subjects $n$ & 126 & 136 & \\
\hline \multicolumn{4}{|l|}{ At enrolment (Tie-COPD) } \\
\hline Male & $104(82.5)$ & $120(88.2)$ & 0.19 \\
\hline BMI $\mathrm{kg} \cdot \mathrm{m}^{-2}$ & $21.8 \pm 3.2$ & $22.2 \pm 3.4$ & 0.35 \\
\hline Smoking status & & & 0.62 \\
\hline Ex-smokers & $38(30.2)$ & $36(26.5)$ & \\
\hline Smoking index pack-years & $48.1 \pm 26.7$ & $44.7 \pm 21.9$ & 0.52 \\
\hline Duration of COPD days & $179 \pm 436$ & $125 \pm 275$ & 0.97 \\
\hline Respiratory disease & $2(1.6)$ & $4(2.9)$ & 0.69 \\
\hline Previous respiratory medications & $13(10.3)$ & 16 (11.8) & 0.71 \\
\hline \multicolumn{4}{|c|}{ Baseline before bronchodilator spirometry } \\
\hline \multicolumn{4}{|c|}{ Baseline after bronchodilator spirometry } \\
\hline FEV 1 L & $2.00 \pm 0.55$ & $2.11 \pm 0.52$ & 0.11 \\
\hline FEV $1 \%$ pred & $82.2 \pm 17.9$ & $83.0 \pm 16.6$ & 0.68 \\
\hline FVC L & $3.26 \pm 0.76$ & $3.38 \pm 0.72$ & 0.18 \\
\hline $\mathrm{FEV}_{1} / \mathrm{FVC}$ ratio & $61.2 \pm 7.6$ & $62.2 \pm 6.9$ & 0.25 \\
\hline Reversibility $^{+}$ & $22(17.5)$ & 29 (21.3) & 0.43 \\
\hline GOLD stage $\mathrm{e}^{\S}$ & & & 0.60 \\
\hline 1 & $72(57.1)$ & 82 (60.3) & \\
\hline ॥ & $54(42.9)$ & $54(39.7)$ & \\
\hline \multicolumn{4}{|l|}{ CAT score ${ }^{f}$} \\
\hline Mean score & $4.0 \pm 3.3$ & $4.5 \pm 4.2$ & 0.53 \\
\hline Distribution & & & 0.22 \\
\hline$<10$ & 119 (94.4) & $123(90.4)$ & \\
\hline Respiratory medications & & & 0.35 \\
\hline Use of respiratory medications & 41 (32.5) & 37 (27.2) & \\
\hline No respiratory medications & 85 (67.5) & 99 (72.8) & \\
\hline Bronchodilators & & & 0.54 \\
\hline Use of bronchodilators & $27(21.4)$ & $25(18.4)$ & \\
\hline No bronchodilators & $99(78.6)$ & $111(81.6)$ & \\
\hline Smoking status & & & 0.73 \\
\hline Never-smokers & $28(22.2)$ & 25 (18.4) & \\
\hline Current smokers & $59(46.8)$ & 68 (50.0) & \\
\hline Quit smoking & $39(31.0)$ & $43(31.6)$ & \\
\hline
\end{tabular}

Data are presented as mean \pm SD or $n(\%)$, unless otherwise stated. Percentages may not sum to 100 because of rounding. Tie COPD: Tiotropium in Early COPD (chronic obstructive pulmonary disease); BMI: body mass index; FEV1: forced expiratory volume in $1 \mathrm{~s}$; FVC: forced vital capacity; GOLD: Global Initiative for Chronic Obstructive Lung Disease; CAT: COPD Assessment Test; mMRC: modified Medical Research Council; CCQ: Clinical COPD Questionnaire. " : there were no significant between-group differences for characteristics at enrolment. The analysis set included patients who underwent both Tie-COPD and post-Tie-COPD follow-up and had at least one available spirometric data measurement after bronchodilator use at Tie-COPD and at least one measurement at post-Tie-COPD follow-up; " $p$-values for continuous variables were calculated using t-test or the Wilcoxon rank-sum test, and $p$-values for categorical variables were calculated using the Chi-squared test; ${ }^{+}$: defined as an FEV1 value obtained after bronchodilator use that increased by $\geqslant 200 \mathrm{~mL}$ and by $\geqslant 12 \%$ from the measurement obtained before bronchodilator use; ${ }^{\S}$ : the GOLD staging system is used to assess the severity of lung disease. Stages range from 1 to 4 , with higher stages indicating more severe disease. Stage 1 (mild disease) is defined as FEV $1 \geqslant 80 \%$ of the predicted value, and stage 2 (moderate disease) as FEV $150-79 \%$ pred; ${ }^{f}$ : scores on the CAT range from 0 to 40, with higher scores indicating more severe disease; \#\#: the mMRC dyspnoea scale ranges from 0 to 4, with higher scores indicating more severe breathlessness; ${ }^{\text {१ी: }}$ CCQ scores range from 0 to 6, with higher scores indicating worse clinical control. 

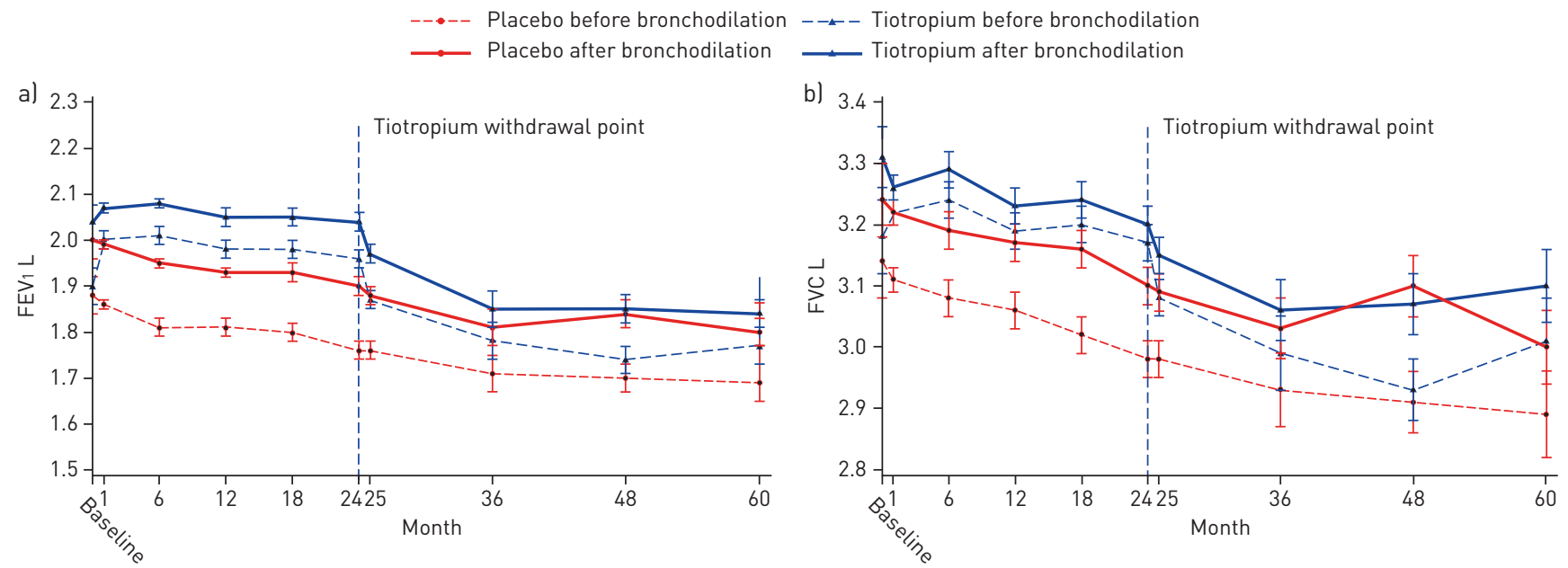

FIGURE 2 Mean forced expiratory volume in $1 \mathrm{~s} \mathrm{(FEV} 1$ ) and forced vital capacity (FVC) before and after bronchodilator use. a) Tiotropium resulted in a significantly higher FEV1 both before and after bronchodilator use than placebo at each visit from month 1 to month 25 (ranges of mean differences $0.10-0.2 \mathrm{~L}$ in FEV1 before bronchodilator use and 0.07-0.12 L in FEV1 after bronchodilator use; $p<0.001$ for all comparisons). b) FVC before bronchodilator use was significantly higher in the tiotropium group than in the placebo group at each visit from month 1 to month 24 (ranges of mean differences $0.10-0.19 \mathrm{~L}$ ) and there was significant difference of $0.09 \mathrm{~L}$ in FVC after bronchodilator use only at month 6 between the two groups ( $p<0.05$ for all comparisons). However, there was no significant difference in FEV 1 and FVC either before or after bronchodilator use between the two groups at each visit of tiotropium withdrawal from 1 to 3 years (ranges of mean differences $0.04-0.08 \mathrm{~L}$ in FEV 1 both before and after bronchodilator use; 0.03-0.12 L in FVC before bronchodilator use; and 0.02-0.09 L in FVC after bronchodilator use; p>0.05 for all comparisons). Bars indicate $\pm 1 \mathrm{SE}$.

\section{Discussion}

This observational follow-up study from the Tie-COPD trial showed that discontinuity of tiotropium in patients with early-stage COPD decreased the differences from patients who had undergone 2 years of regular treatment with tiotropium with respect to spirometry, COPD exacerbations, symptom scores and quality-of-life and dyspnoea scores.

To the best of our knowledge, the present study is the first to assess whether discontinuation of tiotropium alters its beneficial effects on spirometry parameters and COPD exacerbations resulting from 2 years of regular treatment with tiotropium in patients with early-stage COPD.

Bronchodilators alleviate airway limitation mainly by altering airway smooth muscle tone and improving expiratory flow, and are considered to be central to the management of patients with stable COPD [23-24]. Previous clinical trials have demonstrated that tiotropium reduces acute exacerbations, improves symptoms and quality of life, reduces the use of rescue medicine and lowers mortality in patients with early-stage COPD $[8,25-28]$. These results indicate the substantial efficacy of early intervention with tiotropium in patients with COPD, but can tiotropium be withdrawn after obtaining these beneficial effects? To our knowledge, no previous studies conducted follow-up assessments to explore this question. Moreover, previous studies have revealed worsening of COPD after withdrawal of inhaled treatments, among which inhaled corticosteroids are the most typical, and common adverse effects were worsening of lung function and symptoms and increases in acute exacerbations [29-33]. Similar results were reported after withdrawal of tiotropium with respect to worsening of the transition dyspnoea index and decreases in the peak expiratory flow rate and health status [18].

In the present study, the effect of continuous improvement of pulmonary function as indicated by FEV 1 can be sustained for $\sim 1$ month after withdrawal of tiotropium. However, no differences were observed in FEV1 and FVC between the two groups during the 1-3 years of withdrawal of tiotropium; a similar result was observed in the annual decline of FEV1 and FVC, suggesting that the continuous improvement of lung function was not maintained after the withdrawal of tiotropium. Additionally, the incidence of acute exacerbations in both groups was comparable after the withdrawal, suggesting that the reduction in acute exacerbations was not sustained after tiotropium withdrawal. Moreover, the improvements in CAT and CCQ scores were sustained for 1 year after tiotropium withdrawal, but these scores became equal between the two groups after 1 year, and no continuous improvement in the mMRC score occurred after tiotropium withdrawal. This indicates that the continuous tiotropium-induced improvement in symptoms and quality of life can last for $\geqslant 1$ year.

Our results support prior reports of tiotropium withdrawal. The present study demonstrated an acute and persistent worsening in lung function as indicated by the FEV1, symptom score, quality-of-life score and 
TABLE 2 Changes in forced expiratory volume in $1 \mathrm{~s}$ (FEV1) and forced vital capacity (FVC) before and after bronchodilator use after withdrawing tiotropium in early chronic obstructive pulmonary disease $(\mathrm{COPD})^{\#}$

\begin{tabular}{|c|c|c|c|c|}
\hline & Placebo & Tiotropium & Difference (tiotropium - placebo) ${ }^{\pi}$ & p-value \\
\hline Subjects $\mathrm{n}$ & 126 & 136 & & \\
\hline \multicolumn{5}{|l|}{ FEV1 L } \\
\hline \multicolumn{5}{|c|}{ Before bronchodilator use } \\
\hline Month 25 & $1.79 \pm 0.02$ & $1.89 \pm 0.02$ & $0.10(0.04-0.16)$ & 0.0018 \\
\hline Month 36 & $1.71 \pm 0.04$ & $1.78 \pm 0.04$ & $0.07(-0.02-0.15)$ & 0.12 \\
\hline Month 48 & $1.70 \pm 0.03$ & $1.74 \pm 0.03$ & $0.04(-0.03-0.11)$ & 0.23 \\
\hline Month 60 & $1.69 \pm 0.04$ & $1.77 \pm 0.04$ & $0.08(-0.04-0.19)$ & 0.18 \\
\hline \multicolumn{5}{|c|}{ After bronchodilator use } \\
\hline Month 25 & $1.92 \pm 0.02$ & $1.99 \pm 0.02$ & $0.07(0.01-0.13)$ & 0.0145 \\
\hline Month 36 & $1.81 \pm 0.04$ & $1.85 \pm 0.04$ & $0.04(-0.04-0.12)$ & 0.31 \\
\hline Month 48 & $1.84 \pm 0.03$ & $1.85 \pm 0.03$ & $0.008(-0.06-0.07)$ & 0.79 \\
\hline Month 60 & $1.80 \pm 0.03$ & $1.84 \pm 0.03$ & $0.04(-0.05-0.13)$ & 0.36 \\
\hline \multicolumn{5}{|l|}{ FVC L } \\
\hline \multicolumn{5}{|c|}{ Before bronchodilator use } \\
\hline Month 25 & $3.02 \pm 0.03$ & $3.10 \pm 0.04$ & $0.08(-0.01-0.18)$ & 0.09 \\
\hline Month 36 & $2.93 \pm 0.06$ & $2.99 \pm 0.06$ & $0.06(-0.08-0.19)$ & 0.41 \\
\hline Month 48 & $2.91 \pm 0.05$ & $2.93 \pm 0.05$ & $0.03(-0.09-0.14)$ & 0.67 \\
\hline Month 60 & $2.89 \pm 0.07$ & $3.01 \pm 0.07$ & $0.12(-0.07-0.30)$ & 0.21 \\
\hline \multicolumn{5}{|c|}{ After bronchodilator use } \\
\hline Month 25 & $3.13 \pm 0.03$ & $3.17 \pm 0.03$ & $0.04(-0.04-0.12)$ & 0.36 \\
\hline Month 36 & $3.03 \pm 0.05$ & $3.06 \pm 0.05$ & $0.02(-0.84-0.13)$ & 0.66 \\
\hline Month 48 & $3.10 \pm 0.05$ & $3.07 \pm 0.05$ & $-0.02(-0.13-0.08)$ & 0.67 \\
\hline Month 60 & $3.00 \pm 0.06$ & $3.10 \pm 0.06$ & $0.09(-0.06-0.26)$ & 0.23 \\
\hline
\end{tabular}

Data are presented as mean $\pm \mathrm{SE}$, unless otherwise stated. ${ }^{\#}$ : values were measured from month 36 until the end of the study (follow-up from 36 to 60 months after withdrawing tiotropium in early COPD). Multiple linear regression was adopted for each follow-up. For each follow-up visit, the measured value was the dependent variable, and covariates included the individual baseline value, smoking status across the whole follow-up, bronchiectasis status, treatment allocation and participating centre as covariates: ๆ: the difference was calculated as the value in the tiotropium group minus the value in the placebo group.

TABLE 3 Annual decline in forced expiratory volume in $1 \mathrm{~s}$ (FEV1) and forced vital capacity (FVC) before and after bronchodilator use after withdrawing tiotropium in early chronic obstructive pulmonary disease (COPD) ${ }^{\#}$

\begin{tabular}{|c|c|c|c|c|}
\hline & \multicolumn{3}{|c|}{ Decline per year } & \multirow[t]{2}{*}{ p-value } \\
\hline & Placebo & Tiotropium & Difference $(95 \% \mathrm{Cl})^{\pi}$ & \\
\hline Subjects $\mathrm{n}$ & 126 & 136 & & \\
\hline \multicolumn{5}{|l|}{ FEV $1 \mathrm{~mL}$} \\
\hline Before bronchodilator use & $31 \pm 21$ & $21 \pm 20$ & $10(-47-67)$ & 0.73 \\
\hline After bronchodilator use & $68 \pm 16$ & $48 \pm 16$ & $20(-24-64)$ & 0.37 \\
\hline \multicolumn{5}{|l|}{ FVC $\mathrm{mL}$} \\
\hline Before bronchodilator use & $40 \pm 35$ & $26 \pm 33$ & $14(-80-107)$ & 0.77 \\
\hline After bronchodilator use & $59 \pm 31$ & $23 \pm 29$ & $36(-46-118)$ & 0.39 \\
\hline \multicolumn{5}{|c|}{$\begin{array}{l}\text { Data are presented as mean } \pm \text { SE, unless otherwise stated. " } \text { : values were measured from month } 36 \text { until } \\
\text { the end of the study (follow-up from } 36 \text { to } 60 \text { months after withdrawing tiotropium in early COPD). Multiple } \\
\text { linear regression was adopted for each follow-up. For each follow-up visit, the measured value was the } \\
\text { dependent variable, and covariates included the individual baseline value, baseline smoking status, } \\
\text { treatment allocation and participating centre. Additionally, for } 36-60 \text { months, the } p \text {-value was computed by } \\
\text { using the individual baseline value, smoking status across the whole follow-up, bronchiectasis status, } \\
\text { treatment allocation and participating centre as covariates; " } \text { : the difference was calculated as the value in } \\
\text { the placebo group minus the value in the tiotropium group. }\end{array}$} \\
\hline
\end{tabular}




\begin{tabular}{|c|c|c|c|c|}
\hline & Placebo & Tiotropium & $\begin{array}{l}\text { Relative risk for tiotropium } \\
\text { versus placebo }(95 \% \mathrm{CI})\end{array}$ & p-value \\
\hline Subjects $\mathrm{n}$ & 126 & 136 & & \\
\hline \multicolumn{5}{|l|}{ Exacerbations per patient-year" } \\
\hline Moderate & $0.06 \pm 0.01$ & $0.06 \pm 0.01$ & $0.98(0.55-1.77)$ & 0.96 \\
\hline Severe & $0.04 \pm 0.01$ & $0.02 \pm 0.01$ & $0.65(0.27-1.58)$ & 0.34 \\
\hline Of moderate or worse severity & $0.10 \pm 0.02$ & $0.08 \pm 0.01$ & $0.86(0.54-1.38)$ & 0.52 \\
\hline
\end{tabular}

Data are presented as mean $\pm \mathrm{SE}$, unless otherwise stated. \#: exacerbation frequency per patient-year was referred to as the number of exacerbations for a single patient per year; " : the relative risks in these categories were calculated using of Poisson regression corrected for treatment exposure and overdispersion.

acute exacerbation rate over a 1-year period until these parameters were comparable with those in the placebo group. The worsening of lung function, symptoms and health status in patients who withdrew from tiotropium emphasises the need for continuation of maintenance treatment, especially in patients with early-stage COPD.

This study has two main strengths. First, all patients had early-stage COPD. Most of these patients had mild symptoms and rarely used medication, which resulted in a very high proportion of patients with treatment termination after withdrawal. This situation provided a basis for the study of long-term treatment or intermittent treatment of early-stage COPD. Second, both the smoking status and medication use were documented, and patients with a history of using anticholinergic drugs during follow-up were excluded.

A relatively small sample size was one of limitation in this observational study, which was insufficient to detect the difference of the annual decline rate in both FEV1 and FVC between tiotropium and placebo groups before and after discontinuation of tiotropium. Despite this, there was significant difference of the annual decline rate of FEV1 and FVC between groups in a larger sample of the Tie-COPD trial subjects [11]. Another limitation is that not all patients were followed-up for 3 years. The study included 1-, 2- and 3 -year follow-ups, but during all these follow-up durations, the differences between the groups after drug withdrawal decreased or even disappeared.

In conclusion, the lung function of the patients who had received regular treatment with tiotropium for 2 years began to decline after tiotropium was withdrawn, indicating that long-term regular medication is needed to maintain continuous improvement in pulmonary function by tiotropium.

Acknowledgements: We thank Ming Tong, Ben Zhang and Yanan Shen (Rundo International Pharmaceutical Research and Development, Shanghai, China) for contributions in statistical support. We also thank Angela Morben (Liwen Bianji, Edanz Editing China, Beijing, China), for editing the English text of a draft of this manuscript. We thank Qinglu Zheng (Guangdong BOSSsunwen Group, Guangzhou, China) for editing the figure in this manuscript.

Author contributions: C. Li contributed for figures, data collection, data analysis, data interpretation and writing. Y. Zhou contributed to the literature search, figures, data collection, data analysis, data interpretation and writing. S. Liu contributed to data collection. M. Zheng contributed to data collection. J. Zheng contributed for data collection. H. Peng contributed to data collection. Z. Deng contributed to data collection. N. Zhong contributed to data interpretation. P. Ran contributed for literature search, figures, study design, data collection, data analysis, data interpretation and writing.

Conflict of interest: None declared.

Support statement: Supported by grants from the National Key Technology Research and Development Program of the 12th and 13th National 5-Year Development Plan (2012BAI05B01 and 2016YFC1304100) and the Science and Technology Program of Guangzhou (201504010018). Funding information for this article has been deposited with the Crossref Funder Registry.

\section{References}

1 Fang L, Gao P, Bao H, et al. Chronic obstructive pulmonary disease in China: a nationwide prevalence study. Lancet Respir Med 2018; 6: 421-430.

2 Wang C, Xu J, Yang L, et al. Prevalence and risk factors of chronic obstructive pulmonary disease in China (the China Pulmonary Health [CPH] study): a national cross-sectional study. Lancet 2018; 391: 1706-1717. 

groups in 1990 and 2010: a systematic analysis for the Global Burden of Disease Study 2010. Lancet 2012; 380: 2095-2128.

4 Mathers CD, Loncar D. Projections of global mortality and burden of disease from 2002 to 2030. PLoS Med 2006; 3: e442.

5 Zhong $\mathrm{N}$, Wang C, Yao W, et al. Prevalence of chronic obstructive pulmonary disease in China: a large, population-based survey. Am J Respir Crit Care Med 2007; 176: 753-760.

6 Wise R, Connett J, Weinmann G, et al. Effect of inhaled triamcinolone on the decline in pulmonary function in chronic obstructive pulmonary disease. N Engl J Med 2000; 343: 1902-1909.

7 Calverley PM, Anderson JA, Celli B, et al. Salmeterol and fluticasone propionate and survival in chronic obstructive pulmonary disease. N Engl J Med 2007; 356: 775-789.

8 Decramer M, Celli B, Kesten S, et al. Effect of tiotropium on outcomes in patients with moderate chronic obstructive pulmonary disease (UPLIFT): a prespecified subgroup analysis of a randomised controlled trial. Lancet 2009; 374: 1171-1178.

9 Bhatt SP, Soler X, Wang X, et al. Predictors of lung function decline in smokers in COPDGene phase 2. Am J Respir Crit Care Med 2015: A2433.

10 Fang L, Gao P, Bao H, et al. Chronic obstructive pulmonary disease in China: a nationwide prevalence study. Lancet Respir Med 2018; 6: 421-430.

11 Zhou Y, Zhong NS, Li X, et al. Tiotropium in early-stage chronic obstructive pulmonary disease. $N$ Engl J Med 2017; 377: 923-935.

12 Anthonisen NR, Connett JE, Kiley JP, et al. Effects of smoking intervention and the use of an inhaled anticholinergic bronchodilator on the rate of decline of FEV1. The Lung Health Study. JAMA 1994; 272: 1497-1505.

13 Pauwels RA, Löfdahl CG, Laitinen LA, et al. Long-term treatment with inhaled budesonide in persons with mild chronic obstructive pulmonary disease who continue smoking. European Respiratory Society Study on Chronic Obstructive Pulmonary Disease. N Engl J Med 1999; 340: 1948-1953.

14 Vestbo J, Sørensen T, Lange P, et al. Long-term effect of inhaled budesonide in mild and moderate chronic obstructive pulmonary disease: a randomised controlled trial. Lancet 1999; 353: 1819-1823.

15 Burge PS, Calverley PM, Jones PW, et al. Randomised, double blind, placebo controlled study of fluticasone propionate in patients with moderate to severe chronic obstructive pulmonary disease: the ISOLDE trial. BMJ 2000; 320: 1297-1303.

16 Tashkin DP, Celli B, Senn S, et al. A 4-year trial of tiotropium in chronic obstructive pulmonary disease. $N$ Engl $J$ Med 2008; 359: 1543-1554.

17 Disse B, Speck GA, Rominger KL, et al. Tiotropium (Spiriva): mechanistical considerations and clinical profile in obstructive lung disease. Life Sci 1999; 64: 457-464.

18 Adams SG, Anzueto A, Briggs DD Jr, et al. Evaluation of withdrawal of maintenance tiotropium in COPD. Respir Med 2009; 103: 1415-1420.

19 Li X, Zhou Y, Chen S, et al. Early intervention with tiotropium in Chinese patients with GOLD stages I-II chronic obstructive pulmonary disease (Tie-COPD): study protocol for a multicentre, double-blinded, randomised, controlled trial. BMJ Open 2014; 4: e003991.

20 Pellegrino R, Viegi G, Brusasco V, et al. Interpretative strategies for lung function tests. Eur Respir J 2005; 26: 948-968.

21 van der Molen T, Willemse BW, Schokker S, et al. Development, validity and responsiveness of the Clinical COPD Questionnaire. Health Qual Life Outcomes 2003; 1: 13.

22 Jones PW, Harding G, Berry P, et al. Development and first validation of the COPD Assessment Test. Eur Respir J 2009; 34: 648-654

23 Global Initiative for Chronic Obstructive Lung Disease (GOLD). Global Strategy for the Diagnosis, Management, and Prevention of Chronic Obstructive Pulmonary Disease. 2018. Available from: http://goldcopd.org/

24 Celli BR, MacNee W. Standards for the diagnosis and treatment of patients with COPD: a summary of the ATS/ ERS position paper. Eur Respir J 2004; 23: 932-946.

25 Tashkin DP, Celli BR, Decramer M, et al. Efficacy of tiotropium in COPD patients with FEV $1 \geqslant 60 \%$ participating in the UPLIFT ${ }^{\circledast}$ trial. COPD 2012; 9: 289-296.

26 Niewoehner DE, Rice K, Cote C, et al. Prevention of exacerbations of chronic obstructive pulmonary disease with tiotropium, a once-daily inhaled anticholinergic bronchodilator: a randomized trial. Ann Intern Med 2005; 143: 317-326.

27 D'Urzo A, Kerwin E, Overend T, et al. Once daily glycopyrronium for the treatment of COPD: pooled analysis of the GLOW1 and GLOW2 studies. Curr Med Res Opin 2014; 30: 493-508.

28 Troosters T, Sciurba FC, Decramer M, et al. Tiotropium in patients with moderate COPD naive to maintenance therapy: a randomised placebo-controlled trial. NPJ Prim Care Respir Med 2014; 24: 14003.

29 van der Valk P, Monninkhof E, van der Palen J, et al. Effect of discontinuation of inhaled corticosteroids in patients with chronic obstructive pulmonary disease: the COPE study. Am J Respir Crit Care Med 2002; 166 $1358-1363$.

30 Wouters E, Postma D, Fokkens B, et al. Withdrawal of fluticasone propionate from combined salmeterol/ fluticasone treatment in patients with COPD causes immediate and sustained disease deterioration: a randomised controlled trial. Thorax 2005; 60: 480-487.

31 Nadeem NJ, Taylor SJC, Eldridge SM. Withdrawal of inhaled corticosteroids in individuals with COPD - a systematic review and comment on trial methodology. Respir Res 2011; 12: 107.

32 Magnussen H, Disse B, Rodriguez-Roisin R, et al. Withdrawal of inhaled glucocorticoids and exacerbations of COPD. N Engl J Med 2014; 371: 1285-1294.

33 Kunz LIZ, Postma DS, Klooster K, et al. Relapse in FEV1 decline after steroid withdrawal in COPD. Chest 2015; 148: 389-396. 